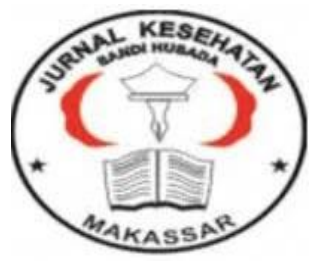

\author{
Jurnal Ilmiah Kesehatan Sandi Husada \\ hhttps://akper-sandikarsa.e-journal.id/JIKSH \\ Vol 9, No, 1, Juni 2020, pp;358-364 \\ p-ISSN: 2354-6093 dan e-ISSN: 2654-4563 \\ DOI: $10.35816 /$ jiskh.v10i2.284
}

\title{
Pengetahuan Pasangan Usia Subur Tentang Suntik Depo Progestin
}

Knowledge of Fertile Age Couples about Progestin Depo Injections

\section{Indryani Indryani ${ }^{1}$, Hasliana Haslan ${ }^{2}$}

1 DIII Kebidanan, Akademi Kebidanan Bina Sehat Nusantara

2 DIII Kebidanan, Akademi Kebidanan Bina Sehat Nusantara

\section{Artikel info}

Artikel history:

Received;15 April 2020

Revised;18 April 2020

Accepted; 30 April 2020

\begin{abstract}
Abstrak.
Pasangan Usia Subur sangat mudah memperoleh keturunanmaka dari itu perlu mengatur kesuburan dengan memiliki pengetahuan yang baik dalam memilih Alat kontrasepsi. Tujuan penelitian adalah Untuk mengetahui Studi tingkat Pengetahuan pasangan usia subur tentang metode suntik Depo progestin di wilayah kerja Puskesmas Ulaweng. Penelitian ini dilakukan dengan cross sectional, yang dilakukan pada pus yang menggunakan suntikan Depo progestin sebanyak 30 orang. Pengumpulan data menggunakan kuisioner dengan pertanyaan suntikan depo progestin. Dalam penelitian ini dilakukan uji univariat. Hasil penelitian dimana berdasarkan pengetahuan mengenai Manfaat alat kontrasepsi Depo Progestin pengetahuan baik 24 orang (80\%) dan pengetahuan kurang 6 orang (20\%), pengetahuan mengenai Jadwal pemberian pengetahuan baik 20 orang (67\%) dan pengetahuan kurang 10 orang (33\%) pengetahuan pus mengenai efek samping pengetahuan baik 25 orang (83\%) dan pengetahuan kurang 5 orang (17\%) pengetahuan mengenai indikasi penggunaan alat kontrasepsi Depo progestin pengetahuan baik masih kurang 14 orang (46\%) dan pengetahuan kurang sebanyak 16 orang ( 54\%) mengenai kontraindiksi pengetahuan baik 17 orang ( 57\%) dan pengetahuan kurang 13 orang (43\%). Kesimpulan dalam penelitian ini dimana pengetahuan PUS yang baik mengenai Manfaat, Jadwal pemberian efek samping dan kontraindikasi mengenai alat kontrasepsi suntik depo progestin dan pengetahuan yang kurang mengenai indikasi suntikan Depo progestin.
\end{abstract}

\footnotetext{
Abstract.

Fertile age couples are very easy to get offspring and therefore need to regulate fertility by having good knowledge in choosing contraception. The purpose of this study was to
} 
determine the study of the level of knowledge of fertile age couples about the injection method of progestin depo in the working area of the Ulaweng Community Health Center. This research was conducted by cross sectional study, which was carried out in pus using injections of Depo progestin as many as 30 people. Data collection using a questionnaire with progestin depo injection questions. In this study a univariate test was conducted. The results of the study where based on knowledge about the benefits of contraception Depo Progestin good knowledge 24 people (80\%) and less knowledge 6 people (20\%), knowledge about the schedule of good knowledge giving 20 people (67\%) and less knowledge 10 people (33\%) knowledge about the side effects of good knowledge 25 people (83\%) and less knowledge 5 people (17\%) knowledge about the indications of contraceptive use Depo progestin good knowledge still less 14 people (46\%) and less knowledge as many as 16 people (54\%) regarding contraindications to the knowledge of both 17 people (57\%) and knowledge of less 13 people (43\%). The conclusion in this study is that good EFA knowledge about benefits, schedule of side effects and contraindications regarding contraceptive injection of depo progestin and lack of knowledge about the indications for Depo progestin injection.

Keywords:

Pasangan usia subur ; Alat kontrasepsi;

Suntikan Depo Progestin;
Coresponden author:

Email: indryani.bidanpendidik@gmail.com

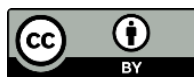

artikel dengan akses terbuka dibawah lisensi CC BY -4.0

\section{Pendahuluan}

Keluarga Berencana merupakan upaya peningkatan kepedulian dan peran masyarakat melalui pendewasaan usia perkawinan (PUP), pengaturan kelahiran, pembinaan ketahanan keluarga, peningkatan kesejahteraan keluarga kecil, bahagia dan sejahtera. (Erna Setyanigrum, 2015). Sasaran program Keluarga Berencana (KB) dibagi menjadi dua sasaran yaitu sasaran langsung dan sasaran tidak langsung, tergantung dari tujuan yang ingin di capai. Sasaran langsungnya adalah Pasangan Usia Subur (PUS) yang bertujuan untuk menurunkan tingkat kelahiran dengan cara penggunaan kontrasepsi secara berkelanjutan. Sedangkan sasaran tidak langsungnya adalah pelaksana dan pengelola Keluarga Berencana (KB) dengan tujuan menurunkan tingkat kelahiran melalui pendekatan kebijaksanaan kependudukan terpadu dalam rangka mencapai keluarga yang berkualitas, keluarga sejahtera. (Zulfa, 2014)

Pasangan Usia Subur (PUS) adalah pasangan suami istri yang keadaan organ reproduksinya berfungsi dengan baik antara umur 20-45 tahun. PUS harus memiliki pengetahuan untuk memilih kontrasepsi yang tepat dalam rangka mewujudkan program Keluarga Berencana (KB) dan mencegah Penyakit Menular Seksual (PMS) yang dapat menjangkiti baik pria maupun wanita PUS. (Devi Pramita, 2015). Dalam menggunakan metode kontrasepsi harus memenuhi syarat kontrasepsi yang telah ditentukan namun belum banyak Pasangan Usia Subur (PUS) mengetahuinya. Kurangnya pengetahuan Pasangan Usia Subur inilah yang membuat PUS mengalami kesulitan didalam menentukan 
pilihan jenis metode kontrasepsi (Manuaba,2013).

Menurut World Health Organization (WHO) pada tahun 2014 penggunaan kontrasepsi meningkat dibelahan dunia, terutama di Asia dan Amerika Latin, secara global pengguna kontrasepsi modern telah meningkat, di Asia telah meningkat dari 60,9\% menjadi 61,6\%, dan merupakan Negara ke 5 di Dunia jumlah penduduk terbanyak yaitu 249 juta jiwa, dengan angka fertilitas atau total fertility rate TFR $(2,6)$ Indonesia masih berada diatas rata-rata TFR Negara Asean yaitu 2,4.

Menurut survei demografi kesehatan Indonesia dimana Pengetahuan tentang alat alat/cara KB merupakan hal yang penting dimiliki sebagai bahan pertimbangan sebelum menggunakannya, informasi mengenai pengetahuan dan pemakaian alat KB diperlukan untuk mengukur keberhasilan program kependudukan,keluarga berencana dan pembangunan keluarga (KKBPK), Suntik KB (29\%) merupakan alat/cara KB paling banyak digunakan oleh wanita kawin,diikuti oleh pil ( $12 \%$ ) ,susuk KB dan IUD masing-masing (5 \%) (SDKI,2017)

Profil Dinas Kesehatan Sulawesi Selatan Tahun 2016, jumlah peserta KB aktif sebanyak 976.933 orang. Sedangkan menurut Data Badan Pusat Statistik Sulawesi Selatan pada Tahun 2017 jumlah peserta KB aktif sebanyak 960.500 orang. pada tahun 2018 jumlah peserta KB aktif sebanyak 1.953 .866 orang. Data yang diperoleh dari Dinas Kesehatan Kabupaten Bone tahun 2016 diperoleh jumlah peserta KB aktif sebanyak 93.044 orang. Dengan rincian pemakaian alat kontrasepsi suntik 59.873 (64,34\%), pengguna pil 28.756 $(30,90 \%)$, IUD sebanyak $582(0,62 \%)$, implant sebanyak 3.724 (4\%), kondom sebanyak $1.580(1,69 \%)$. Pada tahun 2017 jumlah peserta KB aktif sebanyak 6.246 orang dengan klasifikasi yaitu pemakaian alat kontrasepsi suntik sebanyak $4.226(67,65 \%)$, pil sebanyak 1.632 (26, 12\%), IUD sebanyak 34 (0,54\%), implant sebanyak 172 (2,75\%), kondom sebanyak 192 (3,07\%). Pada tahun 2018 jumlah peserta KB aktif sebesar 126.723 orang, dengan pemakaian alat kontrasepsi suntik 29.128 (22.98\%), pil sebanyak 25.087 (19,79\%), IUD sebanyak 3.335 (2,69\%), implant 22.335 (17,62), kondom 6.481 (5,11\%). Dari data tersebut yang mengalami efek samping dari KB suntik Depo Progestin diperkirakan sebanyak 2.144 (50,73\%), terdiri dari yang mengalami amenorea sejumlah 1.230 orang $(29,10 \%)$, yang mengalami kenaikan berat badan sebesar 511 orang (12,09\%), yang mengalami spotting 135 orang (3,19\%) (Data Dinkes Kab. Bone, 2019).

Berdasarkan Data yang diperoleh dari UPT Puskesmas Ulaweng, pada tahun 2017 jumlah peserta KB aktif sebanyak 1.587 peserta, dan akseptor yang menggunakan metode suntikan sebanyak $1282(80,7 \%)$ peserta, pil sebanyak $246(15,5 \%)$ peserta, implant sebanyak $43(2,7 \%)$ peserta, IUD sebanyak $3(0,19 \%)$ peserta, dan penggunaan kondom sebanyak $13(0,81 \%)$ peserta. Sedangkan data pada tahun 2018 jumlah KB aktif sebanyak 1.590 peserta, yang menggunakan metode suntikan $1.008(63,3 \%)$ peserta, pil sebanyak $564(35,4 \%)$ peserta, Implant sebanyak 32 (2,01\%) peserta, IUD sebanyak $1(0,06 \%)$ peserta, dan Pengunaan kondom sebanyak 8 orang (0,5\%) (Data UPT Puskesmas Ulaweng Kab.Bone, 2018).

Sebagai wujud perhatian dalam memberikan kontribusi masalah tersebut, guna mencari solusi terbaik atas permasalahan diatas, maka penulis termotivasi untuk mengkaji lebih dalam studi tingkat pengetahuan pasangan usia subur mengenai metode suntik depo Progestin di Wilayah kerja Puskesmas ulaweng. 


\section{Metode}

Penelitian ini merupakan penelitian deskriptif yang menggunakan rancangan study crosscetional. Populasi dalam penelitian ini adalah Semua Pasangan Usia Subur yang menggunakan alat kontrasepsi adapun sampelnya yaitu Pasangan usia subur yang menggunakan alat kontrasepsi Suntik depo Progestin , adapun tekhnik penarikan sampel yang digunakan yaitu purposive sampling jumlah sampel dalam penelitian ini sebanyak 30 Pasangan usia subur yang menggunakan alat kontrasepsi suntik Depo progestin.

\section{Hasil Dan Pembahasan}

Tabel 1 Distribusi Pengetahuan Responden berdasarkan manfaat tentang alat kontrasepsi suntik Depo Progestin di Wilayah UPT Kerja Puskesmas Ulaweng

\begin{tabular}{c|ccc}
\hline No & Pengetahuan & Frekuensi & Persentase (\%) \\
\hline 1 & Baik & 24 & 80 \\
2 & Kurang & 6 & 20 \\
\hline 3 & Total & 30 & 100 \\
\hline
\end{tabular}

Sumber: Data Primer diolah 2019

Berdasarkan tabel 1 didapatkan bahwa PUS memiliki pengetahuan baik sebanyak 24 orang (80\%) dan pengetahuan PUS kurang sebanyak 6 orang $(20 \%)$ tentang manfaat alat kontrasepsi suntik Depo Progestin. Penelitian ini sejalan dengan penelitian dilakukan oleh Darti Andriani, 2011 dengan jumlah sampel sebanyak 60 responden yang memiliki pengetahuan cukup tentang manfaat Depo Progestin sebanyak 36 akseptor (60\%), sedangkan pengetahuan kurang sebanyak 19 akseptor (31,7\%) dan 5 akseptor yang memiliki pengetahuan baik $(8,3 \%)$. Hal ini menunjukkan bahwa kebanyakan pasangan usia subur sudah mengetahui tentang manfaat alat kontrasepsi suntikan Depo Progestin namun ada juga yang belum mengerti manfaat suntik depo progestin namun tetap menggunakan hal ini disebabkan berbagai faktor salah satunya adalah pendidikan. Dimana Pengetahuan sangat erat hubungannnya dengan pendidikan, dimana diharapkan bahwa dengan pendidikan yang tinggi maka orang tersebut akan semakin luas pula pengetahuannya, sehingga seseorang semakin besar keinginan untuk memanfaatkan pengetahuan, keterampilan dan pendidikan dalam berinteraksi dengan lingkungan khususnya dalam penggunaan dan pemilihan kontrasepsi suntik depo progestin.

Tabel 2 Distribusi Pengetahuan Responden berdasarkan jadwal pemberian tentang alat kontrasepsi suntik Depo Progestin di Wilayah UPT Kerja Puskesmas Ulaweng

\begin{tabular}{c|ccc}
\hline No & Pengetahuan & Frekuensi & Persentase (\%) \\
\hline 1 & Baik & 20 & 67 \\
2 & Kurang & 10 & 33 \\
\hline 3 & Jumlah & 30 & 100 \\
\hline
\end{tabular}

Sumber: Data Primer diolah 2019

Berdasarkan tabel 2 didapatkan dari 30 responden yang diteliti didapatkan 20 orang 
(67\%) yang tahu tentang jadwal pemberian alat kontrasepsi suntik Depo Progestin, dan terdapat 10 orang (33\%) yang tidak tahu tentang jadwal pemberian alat kontrasepsi suntik Depo Progestin. Penelitian ini berbeda dengan penelitian yang dilakukan oleh Asriwati, 2011 yang dilakukan dengan jumlah sampel 20 responden yang memiliki pengetahuan baik tentang jadwal pemberian alat kontrasepsi suntik Depo progestin sebanyak 6 akseptor (30\%), sedangkan pengetahuan tidak tahu mengenai jadwal pemberian sebanyak 14 akseptor (70\%)

Hal ini disebabkan karena kurangnya informasi yang diberikan kepada akseptor mengenai kapan akan berakhir suntikan Depo progestinnya, dan berdasarkan hasil penelitian juga di sebabkan kurangnya kartu peserta akseptor sehingga akseptor lupa kapan akan dilanjutkan suntikannya, dan kurangnya pemahaman akseptor untuk menanyakan hal tersebut.

Tabel 3 Distribusi Pengetahuan Responden berdasarkan efek samping tentang alat kontrasepsi suntik Depo Progestin di Wilayah UPT Kerja Puskesmas Ulaweng

\begin{tabular}{ccc}
\hline Pengetahuan & Frekuensi & Persentase (\%) \\
\hline Baik & 25 & 83 \\
Kurang & 5 & 17 \\
\hline Jumlah & 30 & 100 \\
\hline
\end{tabular}

Sumber: Data Primer diolah tahun 2019

Berdasarkan tabel 3 didapatkan dari 30 responden yang diteliti didapatkan 25 orang (83\%) yang tahu tentang efek samping alat kontrasepsi suntik Depo Progestin, dan terdapat 5 orang (17\%) yang tidak tahu tentang efek samping alat kontrasepsi suntik Depo Progestin. hal ini disebabkan karena minimnya informasi yang di berikan pada saat kunjungan awal penggunaan alat kontrasepsi. Hal ini sejalan dengan penelitian Sri wanti, 2012 dimana dari 171 responden di Puskesmas kassi kassi Makasssar Tahun 2012 terdapat 33 orang ( 21,6\%) yang berpengetahuan baik, 44 orang ( $25,7 \%)$ cukup, 48 orang $(28,1 \%)$ kurang dan 42 orang $(24,6 \%)$ tidak baik namun tidak sejalan dengan penelitian yang dilakukan oleh Sri Jumrah (2011), dimana jumlah sampel sebanyak 87 responden yang memiliki pengetahuan baik tentang efek samping Depo Progestin sebanyak 13 akseptor (14,9\%), sedangkan pengetahuan tidak tahu sebanyak 74 akseptor $(85,1 \%)$. Hal ini menunjukkan bahwa masih banyak pasangan usia subur yang tidak mengetahui efek samping yang dimiliki dari alat kontrasepsi, hal ini disebabkan oleh berbagai faktor salah satunya pendidikan yang rendah, kurang aktifnya dalam mencari informasi sehingga tidak mengetahui kekurangan dari alat kontrasepsi tersebut PUS hanya mengunakan sebagai alat untuk mencegah kehamilan namun tidak mengetahui efek samping yang dimiliki dari alat kontrasepsi yang digunakannya. 
Tabel 4 Distribusi Pengetahuan Responden berdasarkan Indikasi tentang alat kontrasepsi suntik Depo Progestin di Wilayah UPT Kerja Puskesmas Ulaweng

\begin{tabular}{ccc}
\hline Pengetahuan & Frekuensi & Persentase (\%) \\
\hline Baik & 17 & 57 \\
Kurang & 13 & 43 \\
\hline Jumlah & 30 & 100 \\
\hline
\end{tabular}

Sumber: Data Primer diolah tahun 2019

Berdasarkan tabel 4 didapatkan bahwa dari 30 responden yang diteliti didapatkan 17 orang (57\%) yang tidak tahu tentang indikasi alat kontrasepsi suntik Depo Progestin, dan terdapat 13 orang $(43 \%)$ yang tahu tentang indikasi alat kontrasepsi suntik Depo Progestin, berdasarkan hasil penelitian ini didapatkan masih kurangnya pengetahuan PUS mengenai indikasi dari alat kontrasepsi hal ini perlu ditindak lanjuti demi keberhasilan penggunaan alat kontrasepsi dan meminimalkan keluhan keluhan yang dialami pada saat menggunakan alat kontrasepsi. Hal ini sejalan dengan penelitian yang dilakukan Asriwati (2011), dengan jumlah sampel 20 responden yang memiliki pengetahuan baik tentang indikasi alat kontrasepsi suntik Depo Progestin sebanyak 10 orang (50\%), sedangkan pengetahuan tidak tahu sebanyak 10 orang (50\%) akseptor.

Tabel 5 Distribusi Pengetahuan Responden berdasarkan Kontra indikasi tentang alat kontrasepsi suntik Depo Progestin di Wilayah Kerja UPT Puskesmas Ulaweng

\begin{tabular}{ccc}
\hline Pengetahuan & Frekuensi & Persentase (\%) \\
\hline Baik & 14 & 46 \\
Kurang & 16 & 54 \\
\hline Jumlah & 30 & 100 \\
\hline
\end{tabular}

Sumber: Data Primer diolah 2019

Berdasarkan tabel 5 didapatkan dari 30 responden yang diteliti didapatkan 14 orang (46\%) yang tidak tahu tentang indikasi alat kontrasepsi suntik Depo Progestin, dan terdapat 16 orang (54\%) yang tahu tentang kontraindikasi alat kontrasepsi suntik suntik Depo Progestin. hal ini PUS yang tidak mengetahui kontra indikasi penggunaan alat kontrasepsi mengalami berbagai keluhan yang disebabkan dari pemilihan alat kontrasepsi yang tidak tepat. Hal ini tidak sejalan dengan penelitian yang dilakukan Asriwati (2011), dimana jumlah sampel 20 responden yang memiliki pengetahuan baik tentang indikasi alat kontrasepsi suntik Depo Progestin sebanyak 9 orang (45\%), sedangkan pengetahuan tidak tahu sebanyak 11 orang (55\%) akseptor. 


\section{Simpulan Dan Saran}

Berdasarkan hasil penelitian masih Minimnya pengetahuan pasangan usia subur mengenai indikasi dari alat kontrasepsi Suntikan Depo progestin, pengetahuan mengenai pentingnya indikasi alat kontrasepsi sangat diperlukan dengan mengetahui indikasi tersebut pasangan usia subur bisa memilih alat kontrasepsi secara tepat, sehingga meminimalkan keluhan yang dialaminya.

\section{Daftar Rujukan}

Arikunto, (2010) , Metode penelitian suatu pendekatan praktik .Jakarta: PT Rineka Cipta.

Devi Pramita, (2015), Kelangsungan Pemakaian Kontrasepsi. Jakarta: Badan Koordinasi Keluarga Berencana.

Dinas kesehatan Provinsi Sulawesi Selatan. (2016). Data akseptor Keluarga Berencana

Dinas kesehatan Kabupaten Bone. (2018). Data akseptor Keluarga Berencana

Erna Setyanigrum, (2015), Pelayanan keluarga berencana dan kesehatan reproduksi Edisi 2. Jakarta: Cv trans Info media

Handayani asri, (2012), Gambaran pengetahuan ibu tentang alat kontrasepsi suntik depo Progestin Di Puskesmas Mamajang Makassar Tahun 2012. Skripsi

Kementrian Kesehatan RI Pusat Data dan Informasi Kesehatan.(2016). Infodatin situasi dan Analisis keluarga berencana.

Manuaba, (2013). Ilmu Kebidanan Penyakit Kandungan dan KB. Jakarta: Buku Kedokteran EGC.

Survei Demografi dan kesehatan Indonesia, (2017). Jakarta, Indonesia: BKKBN, BPS, Kemenkes dan ICF

Wanti. T sri, (2012), Gambaran tingkat pengetahuan Akseptor KB suntik tentang efek samping Depo Medroxy progesteron Asetat (DMPA) DI Puskesmas Kassi-kassi Makassar

Zulfa, (2014). Pelayanan Keluarga Berencana Dan Kesehatan Rerpoduksi. Yogyakarta: Pustaka Pelajar 